\title{
Sustainable viticulture using organic fertilisers
}

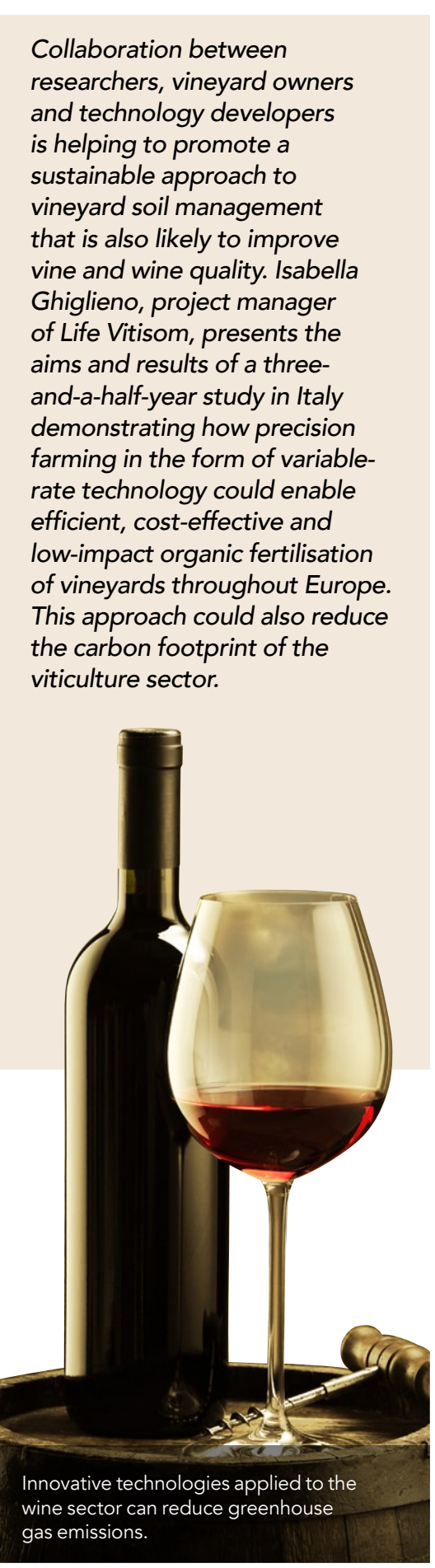

The August 2019 IPCC report proposes adopting farming practices that work with nature,
ther than forcing productivity through rather than forcing productivity through
overuse of fertilisers, as an important overuse of fertilisers, as an important
part of mitigating climate change effects. Machines and fertilisers have enabled intensive farming, in which organic material
is not returned back to the soil, leading to soil degradation and exhaustion of organic matter Now it is clear that efforts must be made to provide agronomic methods that support conservation management practices, work with buyers and growers to encourage land-stewardship, and put soils and their health at the centre of land use. The viticulture sector must also tackle these issues and the comprehensive project undertaken in Italy that is described here is a step in that direction.

\section{PROMOTING SUSTAINABLE}

VINEYARD MANAGEMENT IN ITALY The project 'Life Vitisom' was funded by the LIE programme, the European Union's funding scheme for the out to promote sustaine action. It sets management as part of the priority area of environment and resource efficiency and in support of green and circular economies and soil health.

The development, testing and scale-up of a cost-effective technology for vineyard organic fertilisation was a key part of this endeavour. The University of Milan was the coordinator for the project and was involved in the variable-rate technology (VRT) prototype design and validation, as well as evaluation of soil chemical and biological conditions, vine, grape and wine characteristics and social and economic effects.

The project included technical the form of VRT prototypes for different viticulture contexts that allow the application of organic fertiliser according to the needs of individual vines. The prototypes were tested to identify five diferen machines, each one suitable to be used in specific viticultural contexts.

The various studies were conducted with the cooperation of three Italian wineries (Castello Bonomi, Guido The VRT prototypes were designed and built by Casella Macchine Agricole. Greenhouse gas monitoring was West Systems. Communication and impact assessment were supported by Consorzio Italbiotec.

The work was complemented by efforts to increase the engagement of zviticulture sector operators (wineries, contractors and agricultur the scientific commun public, authorities in order to promote awareness of this sustainable to vineyard soil management and soil protection.

REDUCING THE ENVIRONMENTAL IMPACT OF FERTILISERS USING PRECISION FARMING

Progress in our understanding of soils is showing how organic fertilisers, soil organic matter and reduce the need for chemical fertilisers. Not only does organic matter provide stable nitrogen, it also has positive effects on soil structure, water retention and the availability of nutrients. It can soil by creating better conditions for
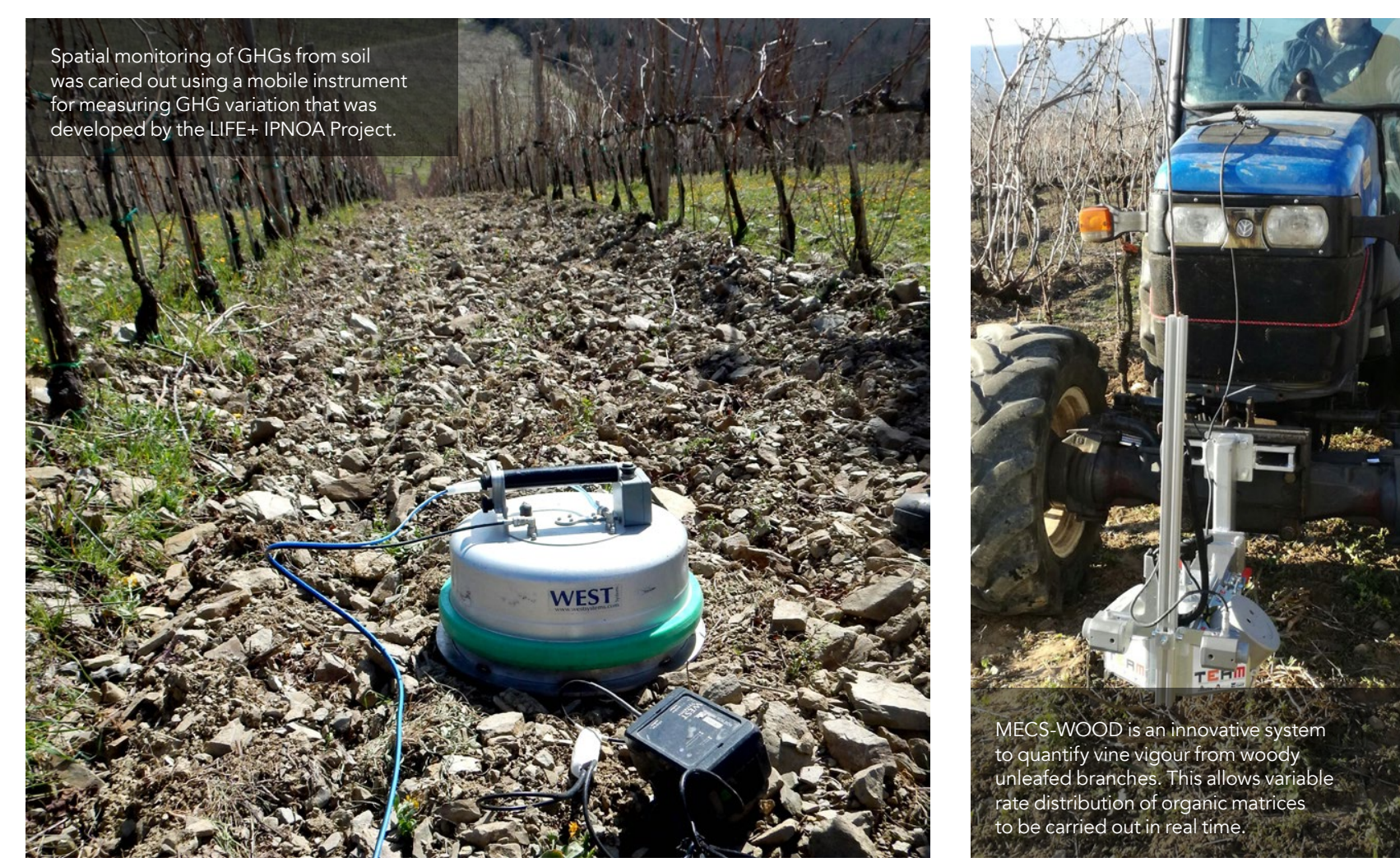

the hospitality of micro-arthropods

and micro-organisms.

We know that greenhouse gases, which contribute to global warming, enter the atmosphere through natural processes, including agricultural soil management. On the other hand, plants have a natur mitigating effect via $\mathrm{CO}_{2}$ uptake by photosynthesis. However, a significan (and reducible) source of greenhouse gas emissionsin sycultural practice is the use

The technology available for the application of organic matter in viticulture is iresources Sustainable solutions for organic fertiliser application will increase both soil and vine quality. Using newly developed advanced agricultural machinery that preserves and protects cultivated land is
added bonus. added bonus. where it is needed has now become possible. It enables less fertiliser use, which in turn saves money. It also helps the environment by enabling growers to reduce greenhouse gas emissions fertilisers. These measures could soon be part of best practice in viticulture. As part of the project undertaken by Life Vilsom, chemical and biological soil parameters were monitored to raise awareness of the physical, chemical and biological soll ferithy. Such studies will hoils in terms of soil structure, oy garc sols in terns of sol structure, organic help to prevent erosion, compaction and organic matter decline.

reduced to infertile desert every year. tis now crucial to promote restorative soil-building practices, such as using organic matter and no-till methods. this will ensure that soil organic content and biologica
can be upgraded.

\section{CARBON UPTAKE AND}

GREENHOUSE GAS EMISSIONS OF VINEYARD ECOSYSTEMS AND SOIL The study outlined here set out envisade the economic and organic fertilistion by using VRT to both reduce the use of chemical fertilisers and reduce the amount of organic matter used in organic

Precision farming using hi-tech instruments to apply fertiliser only where it is needed has now become possible. Organic fertilisation is more efficient if variable-rate technology is used to match the actual needs of vines. Modern agriculture has used up soil 100 times faster than it is replenished
and areas of fertile land are being previously applications but not previously for organic fertilisation of
vineyards. Other studies have found

vineyards. The aim organic fertilisation is more effective if VRT is used to match
the actual needs of vines.

VRT has been gas $\left(\mathrm{N}_{2} \mathrm{O}\right)$ emissions about ten times 


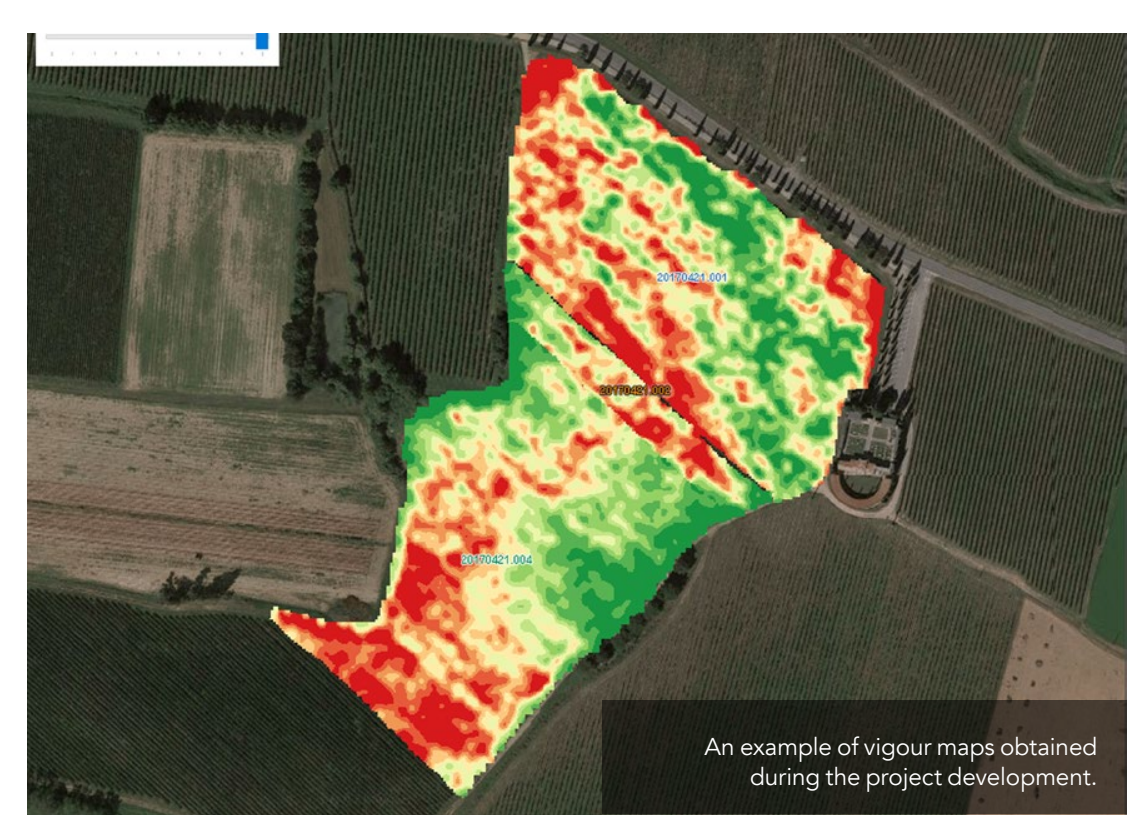

higher than those of organic ones, are preferable.

To provide a framework for vineyard soil and organic matter management that could be replicated elsewhere in Europe and beyond, five prototypes adapted to different pilot contexts in Italy were identified. The project then set out to measure net carbon fluxes (at ecosysten level) and greenhouse gas emissions (at soil level).

Spatial and temporal monitoring of greenhouse gases $\left(\mathrm{CH}_{4}, \mathrm{~N}_{2} \mathrm{O}\right.$ and $\left.\mathrm{CO}_{2}\right)$ emitted directly from soil was carried out to assess the effect of different organic matter management methods. This was period (2017-2018-2019) for five vear sites (including land that was flat, steep and teraced) in different geographical areas of Italy.

In each vineyard, greenhouse gas fertilisers: compost, diger three organic manure. Controls were not fertilised

and either tilled or not tilled. Each of incorporating it or not incorporating it (till or no-till) into the soil. At one test site, urea (with and without incorporation into the soil) was applied.

The aim was to identify peak emission for $\mathrm{N}_{2} \mathrm{O}$ and to highlight seasonal variation in spatial emissions of 作 emissions while manure has the greatest.

Continuous monitoring of net carbon fluxes was done using Eddy Covariance 列

Management methods like this could increase organic matter in vineyard soils and increase soil biodiversity.

\section{This monitoring of soil emissions was} done using a mobile instrument for measuring the variation of greenhouse gases that was developed by the LIFE+ NOA Project. The instrument is housed on a light-tracked vehicle that can be driven remotely. It can measure emissions can then be vield and real-time data October 2019. Results suggested that soil cultivation and canopy and emissions Howner, between the two sites monitored can also be attributed to different climatic conditions and vineyard characteristics. In parallel at the same sites continuous greenhouse gases. The spatial emissions data obtained from the first year of monitoring suggest that solid fraction

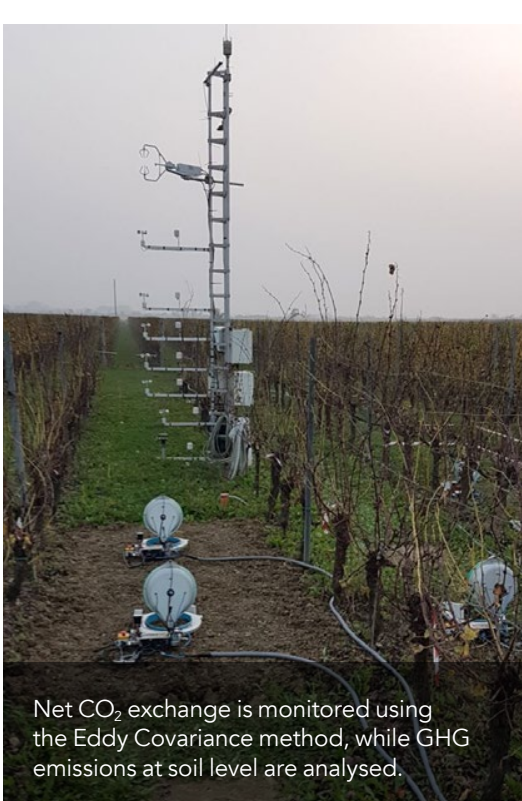

monitoring of $\mathrm{GHG}$ emission was carried out at soil level.

\section{TOWARDS GOOD PRACTICE IN} ORGANIC MATTER MANAGEMENT

Additional aspects of the project worth mentioning were: the implementation vine vigour from annual wood (WI index); odorimetric analysis of different components of applied organic quality; and monitoring of the quality of wine production. Finally, life cycle assessment (LCA) analysis, carbon footprint calculations and evaluation of the project were undertaken.

The project, which started in July 2016 and finishes in processing. A final conference will be held and two publications will be available: a 'Manual of Good Practice of Vineyard Organic Matter Management' and a 'Green Paper on European Strategy of Vineyard Soil and Ecosystem Protection?

Management methods like this could increase organic matter in vineyard soils and increase soil biodiversity (by about 5\%). They could also reduce $10 \%$ compared to chemical fertilisers), of organic fertilisers (by about 10\%), matter distribution (by at least 20\%).

\section{Behind the Research} Dr Isabella Ghiglieno

E: ighiglieno.vitisom@gmail.com T: +393333660658 W: www.lifevitisom.com the organic fertilisers was tested by of MECS-VINE technology to evaluate matter; evaluation of biological soil in the last stages of dae 2019 , is now emissions from vineyard soils (by about reduce the odour caused by distribution

Research Objectives

Isabella Ghiglieno studies viticultural soil management specifically, how to improve organic fertilisation.

\section{Detail}

Università degli Studi di Milano - DiSAA Via Celoria 2 trols

Bio

Bio
Isabella Ghiglieno studied "Viticulture and Oenology" followed by a master degree in "Science of production and protection of plants" at University of Milan. Her experience in the wine sector began in 2007, including four years of a research fellowship at Agricultural and Environmental Sciences Department. Since July 2016, she has been Project manager of LIFE15 ENV/T/000392 LIFE VITISOM Project.

Funding

Collaborators

\section{vi Isom}

LIFE15 ENV/T/000392 LIFE VITISOM Thanks to all Project Partners

\section{References}

Life Vitisom. Available at: https://wnw.lifevitisom.com/ laccessed August 2019]

Valenti L. et al. Project, viticulture innovation technology and GHG emission monitoring. BIO Web of Conferences

Change and Land: An IPCC special report on climate management, food security, and greenhouse gas fluxes in

\section{Personal Response}

As a result of this project, do you have a personal Application (com for the best vineyard organic fertilise or not?

III At this stage we are processing three years' worth of for best vineyard organic fertiliser application after this process. Soil management and organic matter application in fact need different years to determine the positive repercussions on vineyard soil and vine health. At this stage monitoring to better cal brate the carbon footprint and LCA assessment, updating coefficienti in software. We can also confirm the conclusion of our prototypes validation so the VRT technology is now available for organic fertilisation of vineyards. change, desertification, land degradation, sustainable land terrestrial ecosystems. Avallable at: hitpp:///www.ipcc.ch/ 